\section{Paediatric crossword puzzle 30}

Manouri P Senanayake ${ }^{1}$, Arjuna Atapattu ${ }^{2}$ Sri Lanka Journal of Child Health, 2016; 45(1): 56

DOI: http://dx.doi.org/10.4038/sljch.v45i1.8091

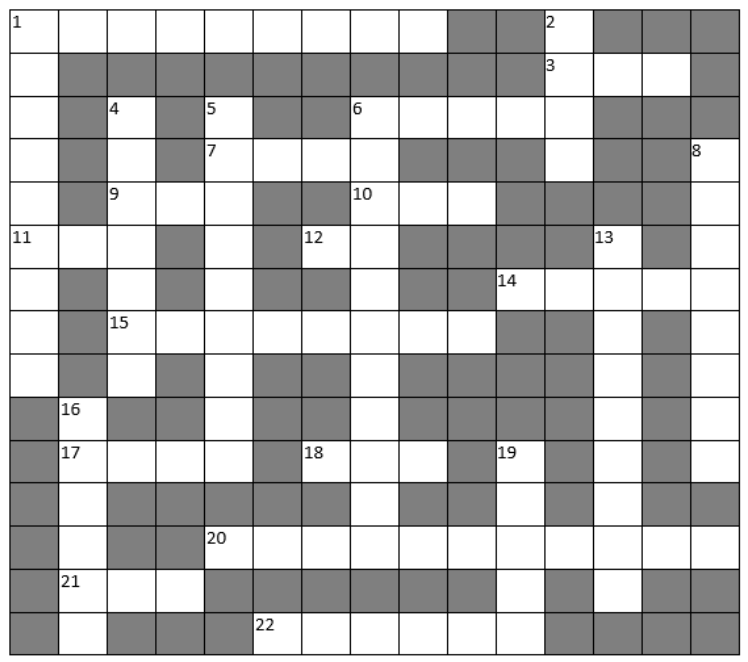

\section{ACROSS}

1. A motor disorder causing learning difficulties due to illegible handwriting and poor organisational skills with normal intelligence

3. Peer perception of child with autism

6. Country of birth of Maria Montessori

7. A repetitive movement

9. Feature of fetal alcohol syndrome involves upper

10. Developmental problems with delayed communication, difficulties in social interaction and repetitive behaviour

11. Welfare support provided by state as finances for disabled (abbrv.)

12. Monologue is when a person talks rather than with

14. Part of toy car that most interests the child with autism

15. Age of maturity

17. A scoring system for autism

18. Abnormality of tongue over rated as cause of speech delay

20. Caused by ligamental laxity

21. Children in foster care (abbrv)

22. Rasopathy considered a male version of a monosomy

\section{DOWN}

1. Sensory processing difficulty for noise can be reduced by wearing ear ....

2. Group of children more affected by ADHD

4. In autism motor milestones are often

5. Term no longer used in Autism Spectrum Disorder

6. Type of ADHD that is difficult to recognise

8. Risk in school setting if autistic

13. Sleep medication

16. The agency that should be prime provider of safety for children

19. Rape is followed by murder mostly when assailant is a .............. person

\footnotetext{
${ }^{1}$ Senior Professor in Paediatrics, ${ }^{2}$ Research Assistant in Paediatrics, University of Colombo
} 